\title{
FUZZY SERVICE QUALITY EVALUATION OF HEALTH CARE SECTORS
}

\author{
P.S. Prema Kumar* \\ Assistant Professor, Mechanical Engineering, Koneru Lakshmaiah Education Foundation, \\ Vaddeswaram, 522502, AP, India.

\section{Dr. G. Rambabu} \\ Assistant Professor, Mechanical Engineering, Andhra University College of Engineering, \\ Visakhapatnam, 530003, AP, India. \\ *Corresponding Author
}

\begin{abstract}
The service quality evaluation of hospitals has important credit for patients and public since it gives hospitals' capabilities to compete in the market and it is very important for the overall development of the health care sector. This research gives a fuzzy multi-criteria decision making (MCDM) problem, to evaluate the service quality of the hospitals of Andhra Pradesh, India. The hospitals are both private and public sectors. The hospitals evaluated are super speciality hospitals. Technique for Order Performance by Similarity to Ideal Solution (TOPSIS) method is adopted for the ranking of the hospitals. The weights of patient's opinion on service quality dimension are included in this method.
\end{abstract}

Key words: Multi-criteria decision making, Service quality evaluation and TOPSIS

Cite this Article: P.S. Prema Kumar and Dr. G. Rambabu, Fuzzy Service Quality Evaluation of Health Care Sectors, International Journal of Advanced Research in Engineering and Technology, 10(4), 2019, pp. 135-139.

http://iaeme.com/Home/issue/IJARET?Volume $=10 \&$ Issue $=4$

\section{INTRODUCTION}

Researchers conducted survey upon the patients and revealed that the service quality as well as the patient satisfaction are very important factors for selecting an hospital for getting the treatment in their next visit. criteria such as, customer satisfaction, service quality must also be measured for all the stakeholders [1]. Therefore, a survey was conducted to measure the service quality through patient satisfaction. It is very difficult to judge the best one with the vogue data. Hence the Order preference method is adopted to give the ranking.

\section{LITERATURE REVIEW}

Service quality is determined by the difference between the service quality given by the hospital and that received by the patient [2], [3] and [4]. From the past research, it becomes seeming that most of the healthcare sectors evaluation approaches are calculated with statistical methods. 
Parasuraman et al. given a five-dimensional instrument by a factor analysis of questionnaire of certain items. Five dimensions are reliability, assurance, tangibles responsiveness, and empathy. This questionnaire consists of twenty-two items [5]; Therefore, there is one more factor added to the previous research i.e. Safety and security and totally six dimensions. The questionnaire has twenty-four items. Five-point Likert scale used to take the patients opinion for the service quality evaluation [6].

\section{METHODOLOGY}

\subsection{Collecting the data}

As mentioned above six dimensions to measure the service quality are taken. Under each dimension there are four subfactors are taken. Totally twenty-four subfactors are taken and the questionnaire prepared using Likert scale. The responses taken from the patients are recorded

\subsection{Calculate the weights}

Based on the expectations of the patients for the treatment, the weights are calculated for all the six dimensions. This data is important while doing the TOPSIS analysis.

\subsection{Apply the TOPSIS method}

The data available is vouge therefore it is a difficult task to choose which one is the best one out of many alternatives. In this condition for Order preference TOPSIS is one of the best methods to give the solution. It is an effective method provides solution for the decision-making problems where there are less numbers of alternatives but have large number of attributes[7] and $[8]$.

\subsection{Ranking the hospitals}

From the results obtained from the TOPSIS method, hospitals are ranked from top to bottom. By this way one can help the patients to select the hospitals as per their expectations for getting a proper treatment.

\section{TECHNIQUE FOR ORDER PREFERENCE BY SIMILARITY TO IDEAL SOLUTION (TOPSIS).}

TOPSIS same time considers the distances to the ideal solution and negative ideal solution for each alternative and selects the best alternative which is closest to the ideal solution and far away from the negative ideal solution. The benefit with this method is that the best alternative can be identified very quickly. A MCDM with $m$ alternatives, which are assessed by $n$ criteria, may be treated as a system of geometry with $m x n$ dimensional space. Decision-making is the procedure to find the best alternative among a set of feasible alternatives[9]. Hwang and Yoon [10] developed the TOPSIS method based on the concept that the selected alternatives should have shortest distance from the positive-ideal solution and the farthest from the negative-ideal solution. This method is used to rank different alternatives starting from the best to the least alternative.

Step 1: Determine Normalized decision matrix

The data collected on service quality parameters from the hospitals is normalized using equation (4.8) 


$$
R_{i j}=\frac{X_{i j}}{\sqrt{\sum X_{i j}^{2}}}
$$

$X_{i j^{-}} \mathrm{j}^{\text {th }}$ service quality parameter of $\mathrm{i}^{\text {th }}$ hospital

$R_{i j^{-}}$The normalized value of $\mathrm{j}^{\text {th }}$ service quality parameter of $\mathrm{i}^{\text {th }}$ hospital

Step 2: Develop a weighted and normalized decision matrix.

$$
v_{\mathrm{ij}}=\mathrm{w}_{\mathrm{j}} * \mathrm{R}_{\mathrm{ij}}
$$

Where ' $w_{j}$ ' is the weight of the $j^{\text {th }}$ service quality parameter

Step 3: Determination of the positive and the negative ideal solutions

$$
\begin{gathered}
v_{j}{ }^{+}=\max \left(v_{i_{j}}\right) \\
v_{j}{ }^{-}=\min \left(v_{i_{j}}\right)
\end{gathered}
$$

Step 4: Calculate the separation measures for each hospital.

The separation from the ideal solution is estimated as below:

$$
S_{i}^{+}=\sqrt{\sum\left(v_{j}^{+}-v_{i j}\right)^{2}}
$$

(for $\mathrm{i}=1,2 \ldots \ldots \ldots \mathrm{m})$

the separation from the negative ideal solution is determined using the following equation:

$$
S_{i}^{-}=\sqrt{\sum\left(v_{j}^{-}-v_{i j}\right)^{2}}
$$

$$
\text { (for } \mathrm{i}=1,2 \ldots \ldots \ldots \mathrm{m})
$$

Step 5: compute the relative closest to the ideal solution $\left(C_{\mathrm{i}}{ }^{*}\right)$

$$
c_{i} *=\frac{s_{i}^{-}}{s_{i}{ }^{+}+s_{i}^{-}}
$$

Where $0<C_{\mathrm{i}}^{*}<1$ and it is called the closeness coefficient.

Step 6: Ranking of hospitals

Ranking is done based on descending order of the closeness coefficient values, i.e. the hospital with the highest closeness coefficient is assigned the topmost rank and the one with the lowest closeness coefficient is given the lowermost rank. The details are tabulated as shown in the Table 2. And Fig 1 compares the hospitals based on closeness coefficient.

Table 2. Ranking of Hospitals

\begin{tabular}{|c|c|c|c|c|c|}
\hline S.No. & Hospital & Si+ & Si- & Ci & Rank \\
\hline 1 & H1 & 0.0261 & 0.0367 & 0.5842 & VII \\
\hline 2 & H2 & 0.0276 & 0.0370 & 0.5727 & IX \\
\hline 3 & H3 & 0.0287 & 0.0328 & 0.5335 & XII \\
\hline 4 & H4 & 0.0268 & 0.0374 & 0.5822 & VIII \\
\hline 5 & H5 & 0.0254 & 0.0400 & 0.6113 & II \\
\hline 6 & H6 & 0.0389 & 0.0240 & 0.3816 & XV \\
\hline 7 & H7 & 0.0259 & 0.0382 & 0.5966 & V \\
\hline 8 & H8 & 0.0380 & 0.0258 & 0.4041 & XIV \\
\hline 9 & H9 & 0.0266 & 0.0389 & 0.5940 & VI \\
\hline 10 & H10 & 0.0257 & 0.0392 & 0.6044 & III \\
\hline 11 & H11 & 0.0277 & 0.0365 & 0.5682 & X \\
\hline
\end{tabular}




\begin{tabular}{|c|c|c|c|c|c|}
\hline S.No. & Hospital & Si+ & Si- & Ci & Rank \\
\hline 12 & $\mathrm{H} 12$ & 0.0251 & 0.0373 & 0.5976 & IV \\
\hline 13 & $\mathrm{H} 13$ & 0.0242 & 0.0406 & 0.6265 & I \\
\hline 14 & $\mathrm{H} 14$ & 0.0337 & 0.0310 & 0.4791 & XIII \\
\hline 15 & $\mathrm{H} 15$ & 0.0287 & 0.0364 & 0.5594 & XI \\
\hline
\end{tabular}

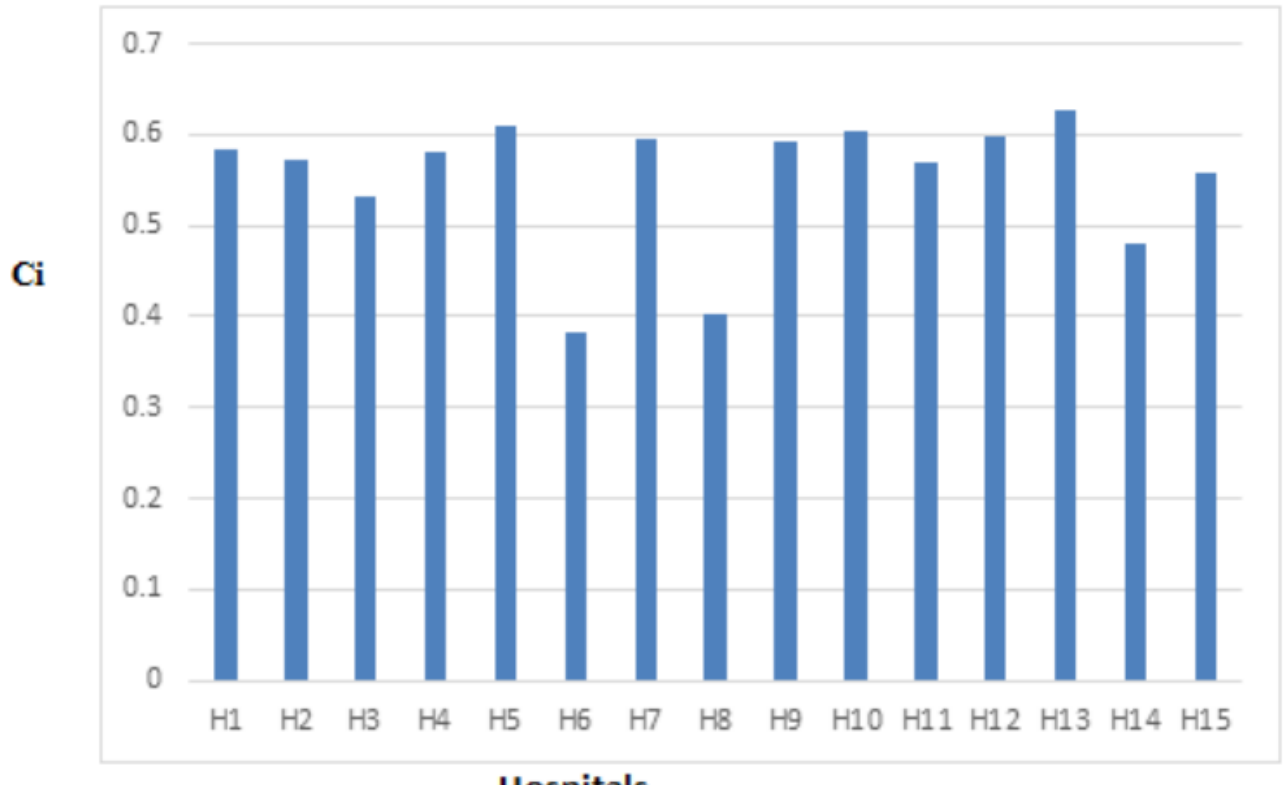

\section{Hospitals}

Figure 1 Hospital ranking with respect to $\mathrm{Ci}$ values

\section{CONCLUSIONS}

A survey was conducted to determine the service quality of the hospitals. Where the patient satisfaction is the output to measure hospital service quality. Six quality measuring dimensions are identified from the past research. From the data collected, it is not possible to judge the best alternatives. For this MCDM problem TOPSIS method is adopted. It involves lesser number of steps. By using this method ranks are given to the hospitals. For the future scope a greater number of quality dimension may be taken and it saves the time if a software is developed for this kind of methods.

\section{REFERENCES}

[1] Nes_e Yalcın Secme, Ali Bayrakdarog lu , Cengiz Kahraman Fuzzy performance evaluation in Turkish Banking Sector using Analytic Hierarchy Process and TOPSIS, Expert Systems with Applications 36 (2009) 11699-11709.

[2] Gronroos C. A service Quality model and Its Marketing Implications. European Journal of Marketing 1982; 18 (1); 36-44

[3] Lewis R C , Bernard H. B, Marketing Aspects of Service Quality in Emerging Perspectives on Service Marketing; American Marketing Association1983; 99-107

[4] Parasuraman A, Zeithaml V, Berry L. A conceptual Model of Service Quality and Its Implications for Future Research. Journal of Marketing 1985; 49; 41-50

[5] Parasuraman A, Zeithaml V, Berry L. SERVQUAL: a multiple-item scale for measuring consumer perceptions of service quality. Journal of Retailing 1988; 64; 12-40 
[6] H. Akdag, T. Kalayci, S. Karag“oz, H. Z"ulfikar, D. Giz, The Evaluation of Hospital Service Quality by Fuzzy MCDM, Applied Soft Computing Journal (2014), http://dx.doi.org/10.1016/j.asoc.2014.06.033

[7] Liguo Fei, Yong Hu, Fuyuan Xiao, Luyuan Chen, and Yong Deng, A Modified TOPSIS Method Based on Numbers and Its Applications in Human Resources Selection, Mathematical Problems in Engineering Volume 2016, Article ID 6145196, 14 pages

[8] Srikrishna S, Sreenivasulu Reddy. A, Vani S A New Car Selection in the Market using TOPSIS Technique, International Journal of Engineering Research and General Science Volume 2, Issue 4, June-July, 2014 ISSN 2091-2730.

[9] Yu-Jie Wang, Hsuan-Shih Lee Generalizing TOPSIS for fuzzy multiple-criteria group decision-making, Computers and Mathematics with Applications 53 (2007) 1762-1772

[10] C L Hwang; Kwangsun Yoon Multiple attribute decision making : methods and applications : a state of the art survey, Berlin ; New York : Springer-Verlag, 1981

[11] Vinodhini A, Dr. Seethalakshmi R and Dr. Sowdamini T, Analyzing the Role of Lean Management in Health Care: A Systematic Literature Review, International Journal of Mechanical Engineering and Technology 9(7), 2018, pp. 303-312.

[12] Dr. V. Mary Diana Richard and MS. S Shenphgavalli, Health Care Management - A Comparative Study among Public and Private Hospitals, Journal of Management, 5(4), 2018, pp. 259-265

[13] Dr. B. Charith, HRM and Its Effect on Employee, Organizational and Financial Outcomes in Health Care Organizations. International Journal of Marketing and Human Resource Management, 6(3), 2015, pp. 32-45.

[14] Dr. D. Padmanaban and Ms. B. Prasanna Soundari. Quality of Health Care In Coimbatore District: A Swot Perspective Leveraging User Insights. International Journal of Management, 7(2), 2016, pp. 259-265. 